
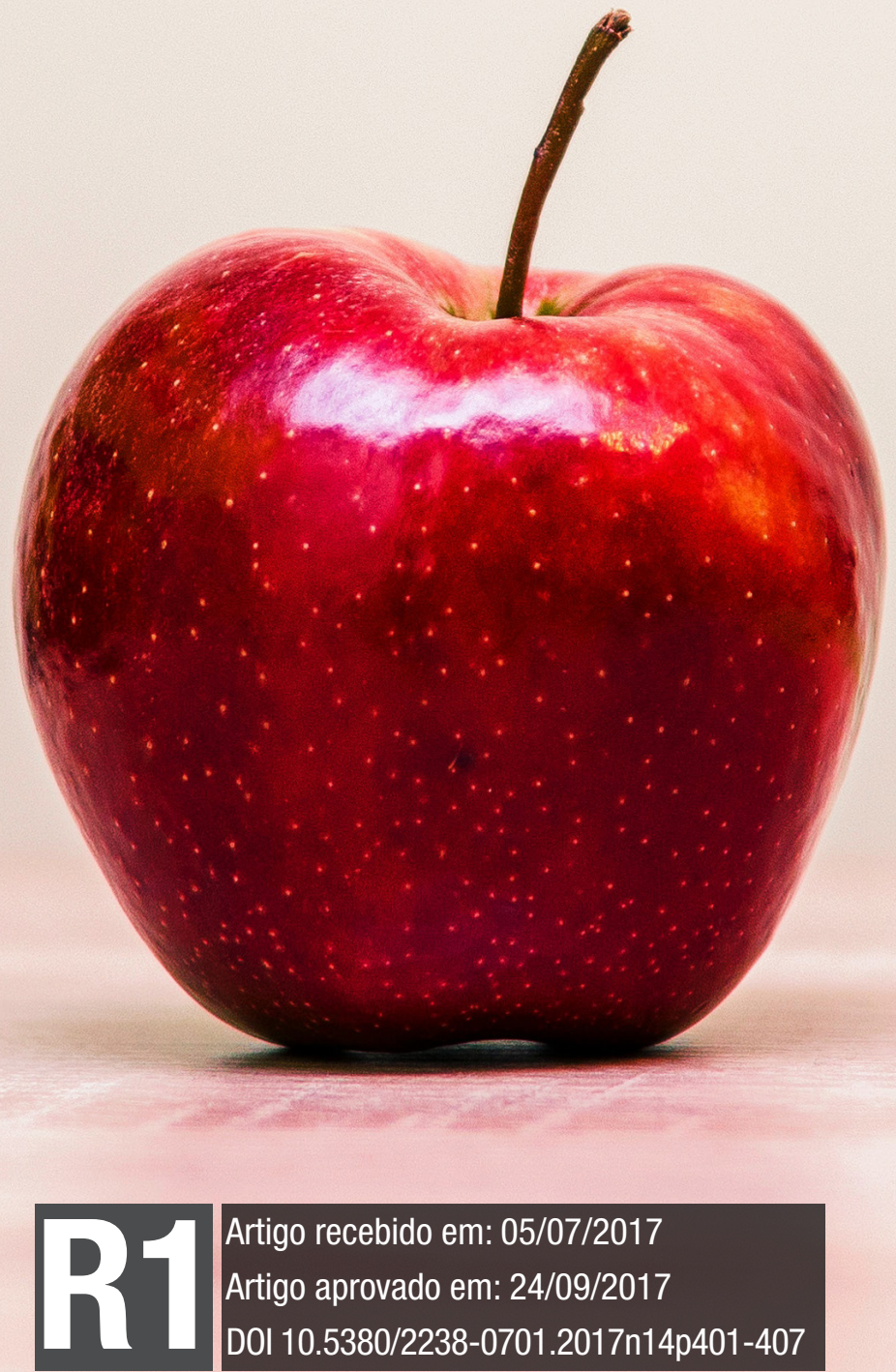
Resenha. Tecnologias digitais. 


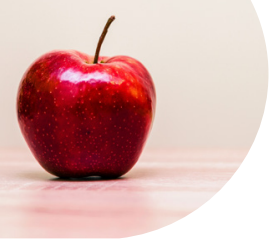

\title{
Construções por meio das tecnologias digitais
}

\author{
Constructions by digital technologies
}

Construcciones por medio de las tecnologías digitales

\author{
LUCIMARA DE SOUSA TEIXEIRA*
}

ADRIANA APARECIDA DE LIMA TERCARIOL**

TERÇARIOL, Adriana Aparecida de Lima; MANDAJI, Mônica dos Santos; CAMAS, Nuria Pons Vilardell; RIBEIRO, Renata Aquino (Orgs.). Da internet para sala de aula: educação, tecnologia e comunicação no Brasil. Jundiaí: Paco Editorial, 2016. 212 p.

A obra aqui resenhada dedica-se à utilização das Tecnologias Digitais da Informação e Comunicação (TDIC) em sala de aula e constitui-se em uma coletânea de textos que abordam as TDIC em contextos educacionais, evidenciando que essas ferramentas criam ambientes diversificados para que o aprendizado seja algo mais contextualizado,

\footnotetext{
* Mestranda no Programa de Mestrado em Gestão e Práticas Educacionais (PROGEPE). Orientadora Educacional no Centro Paula Souza, em uma escola técnica (ETEC), São Paulo, e-mail: lucimarateixeira7@gmail.com

** Pós-doutoranda na Universidade Aberta - Portugal junto ao Departamento de Educação e Ensino a Distância. Doutora em Educação e Currículo pela Pontifícia Universidade Católica de São Paulo. Mestre e Pedagoga pela Faculdade de Ciências e Tecnologia Unesp/Campus de Presidente Prudente/SP. Docente no Curso de Pedagogia (Presencial/Distância) e Programas de Pós-Graduação: em Educação, vinculados à Universidade Nove de Julho (UNINOVE-SP), e-mail: atercariol@gmail.com
} 
significativo, prazeroso e eficiente. Isso se evidencia a partir de cada capítulo, nos quais os autores relatam suas experiências e resultados de pesquisas na área.

Abrindo o primeiro capítulo, a autora Adriana Aparecida de Lima Terçariol explana a respeito do trabalho com Projetos e as Tecnologias Digitais de Informação e Comunicação (TDIC) de forma articulada e enfatiza que, sendo assim, pode-se favorecer com que os talentos individuais sejam valorizados e se agreguem aos projetos que são desenvolvidos. Desse modo, cria-se um ambiente colaborativo que se torna uma oportunidade para potencializar habilidades, competências e compartilhar conhecimentos. Esse capítulo demonstra ainda que o desenvolvimento da formação continuada do docente é fundamental para que novas metodologias sejam implementadas com sucesso nas escolas. Formação essa que pode ser desencadeada em serviço, utilizando metodologias e ferramentas diferenciadas para que os professores em formação possam refletir e se apropriar das TDIC, enquanto recursos pedagógicos.

Adriana Augusta Benigno dos Santos Luz e Anderson Roges Teixeira Góes são autores do segundo capítulo, no qual tratam a educação como um movimento intencional que ultrapassa a sala de aula. Nesse capítulo, os autores relatam a inovação da prática educacional a partir do cenário tecnológico. Os autores argumentam sobre expressão gráfica, na qual os professores abordam de forma integrada tecnologias educacionais como o moodle, moocs etc. Também destacam os Recursos Educacionais Abertos (REA) como cenários de um novo paradigma visual espacial que pode inovar as práticas educacionais com novas metodologias.

No terceiro capítulo, os autores Adriano Sales Coelho, Renata Aquino Ribeiro, Mônica dos Santos Mandaji e Valcenir do Vale Costa demonstram como a rotina escolar é sistematizada a partir de atividades planejadas, nas quais os alunos se tornam protagonistas do seu aprendizado, mesmo com a contradição dos estudiosos. Os autores citam que o aprendizado, de modo informal e formal para uma aula, em pleno século XXI, tende a ser uma comunicação que desenvolve estratégias de aprendizado colaborativo, utilizando softwares e hardwares, podendo envolver um contexto social nesse aprendizado ao utilizar metodologias interativas. A partir de um planejamento adequado, a educação online abre espaços para ambientes diversos na construção de trabalhos colaborativos, por meio de metodologias ativas, demonstrando novas possibilidades e caminhos a serem descobertos pelos professores. 
Iniciando o quarto capítulo, a autora Aneridis Monteiro aborda os modelos de gestão mais produtivos, possibilitando uma nova maneira de administrar a escola. Reconhece a escola como uma organização social eleita para formar autonomia, cidadania e vida profissional, disseminando a informação para que se torne conhecimento; e a globalização da economia faz também parte desse processo, construindo um design educacional. A autora comenta que a gestão democrática foi estabelecida na Constituição de 1988, junto com a Lei de Diretrizes e Bases da Educação (LDB), Lei 9493/96. O capítulo também demonstra que os gestores devem ter a visão da complexidade da escola e que a comunidade escolar tem muito a agregar a esta. Nesse capítulo também é evidenciada a importância das Tecnologias Digitais da Informação e Comunicação (TDIC), isto é, quanto mais se usa essas tecnologias, mais os educadores e educandos estreitam sua relação com o uso de $e$-mails, twitters etc., compartilhando material didático e evitando a delimitação dos conteúdos nas salas de aulas, culminando com a expansão das práticas pedagógicas. A partir desses meios, as TDIC abrangem as redes, espaços nos quais o aprender é um bem que pode ser compartilhado por todos que ali habitam.

No quinto capítulo, os autores Ariana Chagas Gerson Knol, Gláucia da Silva Brito e Renate Kottel Boeno abordam a formação continuada referente ao uso das tecnologias educacionais como aliadas dos professores e relatam práticas do Grupo de Estudos e Pesquisa Professor, Escola e Tecnologias Educacionais (GEPPETE), em que professores de diferentes áreas pesquisam e refletem a respeito da formação de professores. Nesse capítulo, os autores afirmam que as relações pedagógicas devem estabelecer um vínculo entre o conceito e a sua prática pedagógica. Dessa forma, as reflexões serão mais consistentes na utilização da tecnologia e os objetivos podem ser atingidos com mais eficácia, propiciando assim novos aprendizados. O capítulo aborda a Cibercultura, demarcando a educação e a formação continuada como uma possibilidade em que professores e alunos abrem espaço para a troca de informações que, consequentemente, se tornam conhecimento para sociedade.

Os autores Cielo G. Festino e Mônica dos Santos Mandaji, no sexto capítulo, descrevem as narrativas de vida dos diferentes Brasis. Essas narrativas propõem possibilidades de inclusão na educação a distância, envolvendo a sociedade globalizada sobre outros sujeitos do letramento digital, mediadas pela Educação a Distância (EaD). Esses sujeitos, 
professores e tutores, compartilham informações, desenvolvendo o letramento digital, propiciando uma plataforma flexível a partir de um Ambiente Virtual de Aprendizagem (AVA). Projetos narrativos transformam as plataformas EaD em meios mais flexíveis por meio de blogs, jogos, mídias sociais, tornando o letramento digital mais prazeroso para toda comunidade escolar.

Abrindo o sétimo capítulo, as autoras Nuria Pons Vilardell Camas e Gílian Cristina Barros abordam as expectativas e vivências de professores em formação e relatam o projeto piloto Edupesquisa, que é semipresencial. Por meio da plataforma Moodle, esse estudo foi analisado como quanti-qualitativo, no qual tanto alunos como professores realizaram uma formação continuada. Dessa forma, os professores foram selecionados indicando que vivências presenciaram na modalidade EaD e quais possibilidades visualizaram para construção de conhecimentos, a partir dos recursos online disponibilizados.

No oitavo capítulo, a autora Sueli Mainine cita as competências de ensinar e aprender por meio de um trabalho interdisciplinar e afirma que, antigamente, os professores não se preocupavam com sua prática pedagógica, pois acreditavam que não estavam vinculadas com a habilidade de aprender do aluno. A autora relata que as tecnologias digitais também se tornam uma ferramenta importante para o trabalho didático pedagógico, propiciando oportunidades interdisciplinares para o processo de ensino e aprendizagem. Os discentes, assim como os docentes, se tornam sujeitos dos seus saberes. A autora também se refere à dialética existente no cotidiano do aprender por meio de projetos interdisciplinares, uma vez que o aluno se torna protagonista na construção do seu saber a partir desses projetos.

No nono capítulo, os autores Renata Aquino Ribeiro, Gilmar Luis Mazurkievicz e Cláudia Cristina Muller comentam o Mobile Learning Congress da Unesco, realizado em 2013. Esse congresso envolveu mais de 90 países e oportunizou dezenas de publicações. Ressaltam ainda que os professores estão utilizando mais as TDIC, e que a prática pedagógica está se aliando cada vez mais com os dispositivos móveis como, por exemplo, os celulares, os tablets e os laptops. Assim, os dispositivos móveis possibilitam novas práticas para os docentes. Os autores citam que a utilização dos Recurso Educacionais Abertos (REAs) têm ganhado espaço na criação de aplicativos em dispositivos móveis como Mit App Inventor e Visual Class, que são utilizados para criação de jogos. 
Os autores veem como um desafio a utilização de todos esses recursos como espaços formais de aprendizagem, como, por exemplo, as redes sociais Facebook e Twitter, as plataformas Second Life, Pinterest, Moodle, entre outros, como forma de compartilhar conteúdos, sejam textos, imagens ou vídeos. Comentam ainda sobre o PLE - Personal Learning Environment - Ambiente Pessoal de Aprendizagem, no qual os discentes tornam-se gestores do seu próprio aprendizado.

Fechando a obra no décimo capítulo, Renata Aquino Ribeiro e Selma Bessa Sales abordam o letramento digital como um desafio para a educação, propondo um novo desenvolvimento do currículo. As autoras relatam que a educação é um aprendizado colaborativo cuja experiência integra as tecnologias ao currículo da sala de aula, tornando o professor mais proativo na área de letramento digital e inclusão digital. As autoras informam que no novo contexto a função do professor é a de propiciar o desenvolvimento do discente e de seu grupo, concluindo que, atualmente, ele não é somente o transmissor de informações, se tornou o orientador que colabora para o aprendizado de seu aluno. As autoras comentam também neste capítulo sobre o Sistema Público Municipal de Ensino de Fortaleza - CE, que tem por objetivo alfabetizar melhor os alunos que demostram alguma deficiência no domínio tanto da leitura como da escrita. A pesquisa foi de natureza qualitativa e respondeu questões referentes ao acesso, frequência de uso, recursos dos computadores e da internet, formação e experiência docente com o uso da tecnologia.

A importância de um estudo acerca da maneira como são escolhidas as tecnologias usadas dentro e fora das salas de aula propicia diferentes metodologias a serem adotadas como práticas pedagógicas. Por outro lado, promover a formação dos docentes é imprescindível para a implementação dessas práticas, uma vez que docentes muitas vezes desconhecem as potencialidades das novas tecnologias. Faz-se necessário refletir sobre o que apresentar para os discentes a respeito de recursos tecnológicos, visto que a gama existente é muito abrangente. Assim, se não é mais possível conviver sem tais recursos, é fundamental saber como e quando usá-los. Dessa forma, as experiências descritas no livro em questão enriquecem o conhecimento sobre as TDIC de maneira a fazer o leitor pensar em seu uso consciente e de forma articulada a projetos interdisciplinares. 